\title{
CONTENT ANALYSIS OF ENGLISH TEXTBOOK "WHEN ENGLISH RINGS A BELL" FOR JUNIOR HIGH SCHOOL GRADE SEVEN
}

\author{
Lisdayanti Asrun \\ Lio, M.Hum \\ Kamaluddin \\ English Department \\ Halu Oleo University \\ Email: lisdayanti813@gmail.com
}

\begin{abstract}
This research was accomplished to find out whether English textbook "When English Rings A Bell" for Junior High School on seventh grade fulfilled each criterion of textbook evaluation criteria. The researcher used qualitative analysis as the research design. The data source was collected from English textbook "When English Rings A Bell" for Junior High School on seventh grade. The instrument of this study was textbook evaluation criteria. The researcher collected the data by using checklist to evaluate the textbook then analyzing the data shown from the checklist and making some interpretations, and finally describing the results from the assessment table. The result confirmed that English textbook "When English Rings A Bell" for Junior High School on seventh grade was categorized as inappropriate book because there were only four of fourteen subcriteria which were fulfilled, namely the objectives were given in the beginning of the book and each chapter, the topic or materials were suitable with the objectives, there were visual materials relevant with the topic, and the instructions of the exercises were clear and easy to understand in terms of completed by examples, while the rest ten criteria were not fulfilled. It was recommended to the teacher to cover the weaknesses of the book by their teaching style or to find another reference outside this textbook.

Keywords: Textbook, Evaluation Criteria
\end{abstract}

Introduction

Textbooks are chief properties for teachers in supporting students to learn every matter including English. They are the 
underpinning of school training and the major spring of information for teachers. Textbooks function as the root for much of the language input that the learners obtain and the language practice that occur in the classroom. For the EFL learners, textbook becomes the main source of exchange that they have with the language away from the input provided by the teacher. Hutchinson and Torres (1994) propose that the textbook is an almost worldwide constituent of English language teaching and no teaching-learning situation, it seems, is comprehensive until it has its appropriate textbook.

Because of the importance of textbook itself, the researcher perceived that it is important to analyze textbook which is used by the students of Junior high School. In Indonesia, English is firstly taught in Junior High School which means that the students need a good book to be their starting point in learning English. According to Sheldon (1988) in Handayani (2016), we need to evaluate textbooks for two reasons. First, the evaluation will help the teacher or program developer in making decisions on selecting the appropriate textbook. Furthermore, evaluation of the merits and demerits of a textbook will familiarize the teacher with its probable weaknesses and strengths. This will enable teachers to make appropriate adaptations to the material in their future instruction. In this line, Cunningsworth (1995) and Ellis (1997) in Gholami, Noordin, and Rafik-Galea (2017) propose that textbook evaluation can be of three types, namely 'preuse', 'in-use', and 'post-use' evaluations. Evaluation of textbooks for pre-use, or predictive, aims at helping teachers in selecting the most appropriate textbook for a given language classroom by considering its prospective performance. The second type of evaluation aids the teacher to explore the weaknesses or strengths of the textbook while it 
is being used. Finally, post-use, or retrospective evaluation helps the teacher reflect on the quality of the textbook after it has been used in a particular teaching learning situation.

Sriwahyuni (2016) conducted a study entitled "content analysis of English textbooks When English Rings a Bell for junior high school grade VIII". She conducted a research to find out the explicit and implicit content of the English textbook by using the material analysis called Three Level of Analysis proposed by Littlejohn (2009). The result of the analysis showed that the explicit content referred to the physical aspect of the textbook and the sequence main activities offered within the textbook consisted of the textbook's title, published, type, intended audience, age-range, sequence main parts, and the number of chapters.

In this study, the researcher analyzed an English textbook entitled "When English Rings a Bell" for grade seven. This textbook had been revised for four times. The first printing was on 2013, the second printing was on 2014, the third printing was on 2016, and the last printing was on 2017 . This book was arranged by the government through the ministry of education and culture to implement curriculum 2013. This book had big amount of users. Most of school in Indonesia used this book because of several reasons. The first, this book was arranged by education minister which means that the standard is guaranteed by the government. The second, this book is sold in low price, simply by Rp.14000,- the teacher or students can buy 
Literature Review

Definition of Textbook

Nowadays, textbook is a main device to deliver the material to the students. The using of the textbook in the classroom can helps the teachers to provide the materials. The students can use the textbook to practice their understanding about the materials from the teacher. According to Tomlinson (2005), a textbook provides the core materials for a course. Language textbooks cover grammar, vocabulary, pronunciation, functions, and the skills of reading, writing, listening and speaking are included in a textbook for language teaching.

The Criteria of Textbook Evaluation

Jahangard (2007) evaluated the checklist criteria from ten experts, Chastain (1971), Tucker (1975), Cowles (1976), Daoud and Celce-Murcia (1976), Candlin and Breen (1979), River (1981), Williams (1983), Sheldon (1988), Skierso (1991), and Ur (1996). He developed the criteria of textbook evaluation by comparing standard from 10 different sources then compiling those criteria into thirteen criteria to evaluate the textbook.

The first criterion is whether the objectives explicitly laid out in an introduction, and implemented in the material. It means that there is an introduction that attempts to clarify the intended teaching objectives. A good textbook needs to state the goals which the teachers and the learners should achieve. The ultimate goals of the curriculum are clarified. The authors of the book clearly specify the final objectives of the curriculum in vivid words so that the stakeholders know what they are expected to have learnt at the end of the program (long term objectives). Likewise, the short term objectives 
remain specified in the introduction. So the teachers know what the learners should be able to do to demonstrate that they have achieved the intended objectives at the end of each course e.g. at the end of each year in the educational program.

The second criterion is whether the book contains good vocabulary explanation and practice. It means that a textbook should concern with the correspondence between the different senses of the word introduced in the new words sections and the senses which are used in the reading comprehensions. It is needed to show the fact obviously that a word might have several different senses.

The third criterion is whether it approaches educationally and socially acceptable to target community. A good textbook should include all five aspects: structure, function, situation, topic, skills which are reasonable, good enough so that it can be logically acceptable in a certain community.

The fourth criterion is whether it has periodic review and test sections. At the beginning and the end, review exercises are attached sometimes. However they are not enough. It seems better to include tests and review tests at the end of each one of the lessons. It is worth mentioning that the tests should be comparable and compatible with the format and the testing methods which will be employed in the mid- term and final exams.

The fifth criterion is whether the textbook has clear attractive layout and print easy to read. The textbooks are acceptable regarding the clarity and orthographic beauty. However, it would be more appealing if colorful pictures of real people and real environment were used. 
The sixth criterion is whether it contains appropriate visual materials. Visual materials can be defined as the facilities that can be employed by teachers and learners to enhance language learning in classrooms. They may range from simple hand-made realia, charts and pictures to electronic and digital materials. Providing appropriate visual materials means giving information clearly furnished with illustrations that facilitate students in understanding each material, whether it is in reading comprehension or grammar section.

The seventh criterion is whether it has interesting topics and tasks. The topics of readings vary from factual to anecdotal ones and they sometimes are funny stories. It is difficult to judge on behalf of the learners whether those are interesting for them or not. It seems that it would be better if the topics are updated to become more congruent with the taste of the new generation which might be a bit different from that of the authors who designed the books at least ten years ago. Tasks that are very traditional would make students more easily saturated. A good textbook should carries out that problem well.

The eighth criterion is whether the textbook contains clear instructions. Most of the instructions are clear and easy to understand for the learners in the books in the series. Even if the learners might not be familiar with the structures and the lexis used in the instructions, the models given for each group of exercises provide contextual clues for the learners as to what they are expected to do. The bias instructions will create bias answers and learning process.

The ninth criterion is whether the content is clearly organized and graded. Sentences will be too complex for learners to understand. 
It may happen because they did not know the meaning of the new words included in. Planning the content carefully and consisting in series for each material to be slightly more difficult can help students achieve each competency without feeling tired and stressed.

The tenth criterion is whether it contains plenty of authentic language. Authenticity is defined as follows by Johnson and Johnson (1999): Texts are said to be authentic if they are genuine instances of language use as opposed to exemplars devised specially for language teaching purposes. It means that the content of a textbook add the example based in fact. The contextual illustrations can help the learners easily create an imagination on their mind.

The eleventh criterion is whether it contains good grammar presentation and practice. They are aimed at providing the learners with oral practice of the intended grammatical points.

The twelfth criterion is whether it contains fluency practice in all four skills. Fluency means a smooth way of moving. Practice means the actual performance of an activity. In sum, the criteria above indicate that there is no separation between the activities to the other activities. The four skills tested in nature so that students do not gain experience while studying in the four skills.

The thirteenth criterion is whether it encourages learners to develop own learning strategies and to become independent in their learning. A scientist states that "good reader usually browses the whole text before starting to read and pays attention to the organization and structure of the text as well as other parts which are relevant and compatible to the goals of the reading. The explanation above simply is an illustration that successful learners are persons 
who are able to develop his knowledge after completed the learning process by using a textbook."

Research Method

This research used a descriptive qualitative design. It analyzed a textbook which was used in English textbook for Junior High School published by Kementerian Pendidikan dan Kebudayaan.

First of all, the researcher chose the book which was analyzed. The second, the researcher analyzed the textbook by looking at the fulfillment of criteria, those are objectives, good vocabulary and practice, approaches educationally and socially, periodic review, appropriate visual, interesting topics, clear instructions, clear attractive, clear content, plenty of authentic language, good grammar, fluency practice, and encourage learners. But in this research the researcher only focused on seven fulfillments of criteria. The last step was the researcher reported the result in the form of writing. The researcher used content analysis technique to analyze the data.

Findings and Discussion

After analyzing the data, it was found that:

1. Objectives were explicitly laid out in an introduction, and implemented in the material

The first aspect of this criteria could be divided into two questions, namely whether the textbook contains objectives in each chapter and whether this textbook contains objective in the beginning of the book. The first question was fulfilled that this book has an objective in the beginning of each chapter. The objectives were given in the forms of short statements such as in chapter I, the objective is "We will learn to greet, to say sorry, to take leave". 
The second aspect of this criterion is that whether the objectives are suitable with the official syllabus. According to Robert F. Mager (1962), learning objective is something which will be achieved or can be done by the students in particular level and condition. It means that learning objectives must be formulated in sentences which can give clear image regarding what the curriculum expect the students to achieve. However, all chapters simply tell the students what they are going to do without telling them what they will achieve in each chapter. For instance, in chapter I the students will learn to greet, to say sorry, to take leave, to say thank you. This kind of objective will make the students confused and lose of indicator to what will be the measurement of their learning successful.

The third aspect of this criterion is that whether the topics or materials are suitable with the objectives or not. This aspect simply describes the strength of this textbook where the material is simply suitable with the objectives. Most of the content of this textbook is fulfilled by picture of people who are talking. We can say this textbook is strongly focused on daily conversation or using sentences based on context.

2. Good vocabulary explanation and practice

The first aspect is whether there is a vocabulary section in each chapter or not. After doing a complete observation, the researcher did not found any particular section which is related to vocabulary section or similar to words list. However, there were two of eight chapters which provided some alternatives to learn new vocabulary related to the topic.

The second criterion is that whether the vocabulary section consisted of lists of words and their definitions based on the context 
used. This aspect was more appropriate if the vocabulary section consisted of "Verb" words which has dual meaning and should be appropriate with the context. The instruction of picture 4.5 is Here are what we will do. First, we will listen to our teacher say the names of the things in the classroom. Then, we will repeat the words after the teacher one by one. There is no instruction which leads to the use of words in sentences. The students are simply asked to pronounce it after the teacher.

The third criterion is that whether there are vocabulary practices in each chapter. The researcher had tried to find a section which is similar to the vocabulary section above. Since there is no particular vocabulary section in this textbook, the researcher also did not find any vocabulary practices in this textbook.

3. Fluency practice in all four skills

There are four skills in language learning, they are speaking, listening, writing, and reading. Overall, the researcher perceived this textbook was more concern with speaking skills rather than the other skills. It was proved when all chapter consist of dialogues or training how to pronounce the words or the dialog which is given by the teacher.

The other chapter also presents similar section of speaking where students are asked to practice the dialog in front of the class in group. Sometimes, the students are asked to make a simple conversation regarding asking or responding to something based on the format given.

4. Good grammar presentation and practice 
The first criterion is that whether there is a grammar presentation in each chapter. This aspect was not fulfilled because none of the chapters consists of grammar presentation.

All sentences were given without any reasons of forming the sentences. It increases the teacher's burdened to teach or to answer the questions of the students regarding grammar. Even grammar presentation exists, the teacher still teaches the students about grammar but at least it can help the students to understand grammar before the teacher explains it.

5. Appropriate Visual Materials Available

The criterion is that whether there were visual materials available from the book, such as charts, pictures, movies, etc. which were relevant with the topics. This textbook was supported with relevant visual materials. It was provided in all the chapters in this textbook. Using some comic texts are regarded very helpful for students.

6. Clear Instructions

There was only one aspect in this criterion, namely whether the instructions of the exercises or practices were clear and easy to understand.

There were a lot of instructions found in the textbook, and the researcher perceived that the instructions were made in clear language and easy to understand. Below are some examples of instructions which were taken randomly in some chapters:

1. Here are what we will do. First, we will work in pairs. Second, we will interview each other to know what we usually do every day, and the time we do each activity. Then, we will put the information in the table. (p.46) 
2. We will find out and tell our daily activities and the daily activities of one classmate. (p.46)

Those practices provided clear instructions. The instructions used simple word in order to make the students easy to understand the meaning of the instructions. The instructions were also considered easy to understand because they were given in short sentences, such as "We will report our findings in good sentences".

7. Clear attractive layout, print easy to read

The descriptions for this criterion are that (1) the words were correctly spelled and clearly printed, and (2) it consisted of colorful pictures of real people and real environment.

The first criterion is that whether the words in textbook were correctly spelled and clearly printed. The researcher had found 5 errors in spelling, they are:

1. We wil learn to tell the names of the things that we often have in our bags. (p. 63)

2. Weach one of us will write the work in our notebook. (p.97)

The researcher considered that this theory is available to spelling error number 1, 3, 4, and 5. Those kinds of error could be said as human error because there were only one or two missing or over letter in the spelling error. This is a normal condition where the writers had to type 202 pages. So, the correct spellings for those words are, will, souvenir, handwrite, and criticize. Another issue exists in number 2. The writer was error in typing "weach" the researcher had tried to find the exact word to replace the word but none word was suitable. The second aspect is whether it consists of colorful pictures of real people and real environment. This aspect was not fulfilled since this textbook 
does not contain any real picture or environment. All the pictures were made in animation forms.

\section{Conclusion}

The result confirmed that English textbook "When English Rings A Bell" for Junior High School on seventh grade was categorized as inappropriate book because there were only four of fourteen subcriteria which were fulfilled, namely the objectives were given in the beginning of the book and each chapter, the topic or materials were suitable with the objectives, there were visual material and relevant with the topic, and the instructions of the exercises were clear and easy to understand in terms of completed by examples. The rest ten criteria were not fulfilled. It was recommended to the teacher to cover the weaknesses of the book by their teaching style or to find another reference outside this textbook.

References

Cunningsworth, A. (1995). Choosing your Coursebook. Cambridge, Cambridge University Press.

Gholami, R. Noordin, N., \& Rafik-Galea, S. (2017). A through scrutiny of ELT textbook evaluation: A review inquiry. International Journal of Education and Literacy Studies, 5(3).

Handayani, S. (2016). The evaluation of English textbook for grade VII of junior high school in Indonesia. Unpublished Thesis. Bengkulu University.

Hutchinson, Tom \& Eunice Torres. (1994). The Textbook as agent of change. English Language Teaching Journal, 48.

Skierso, A. (1991). Textbook selection and adaptation. In CelceMurcia, M. (ed.) Teaching English as a Second or Foreign Langauge. Newbury House. 
Sriwahyuni, A. (2016). Content analysis of English textbook "When English Rings A Bell" for junior high school grade VII. Unpublished Thesis. State University of Makassar.

Tomlinson, B. (2005). Developing materials for language teaching. London, UK: Continuum. 